IdeAs

Idées d'Amériques

$17 \mid 2021$

Villes et culture dans les Amériques

\title{
Los límites de las estrategias implementadas para la protección de los líderes sociales y sus perspectivas a nivel nacional e internacional
}

Cielo E. Rusinque Urrego

\section{OpenEdition}

Journals

Edición electrónica

URL: https://journals.openedition.org/ideas/10374

DOI: 10.4000/ideas.10374

ISSN: 1950-5701

Editor

Institut des Amériques

Referencia electrónica

Cielo E. Rusinque Urrego, «Los límites de las estrategias implementadas para la protección de los líderes sociales y sus perspectivas a nivel nacional e internacional », IdeAs [En línea], 17 | 2021,

Publicado el 01 marzo 2021, consultado el 04 junio 2021. URL: http://journals.openedition.org/ideas/ 10374 ; DOl: https://doi.org/10.4000/ideas. 10374

Este documento fue generado automáticamente el 4 junio 2021.

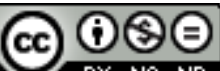

IdeAs - Idées d'Amériques est mis à disposition selon les termes de la licence Creative Commons Attribution - Pas d'Utilisation Commerciale - Pas de Modification 4.0 International. 


\section{Los límites de las estrategias implementadas para la protección de los líderes sociales y sus perspectivas a nivel nacional e internacional}

Cielo E. Rusinque Urrego

\section{En el ámbito nacional de protección}

\section{La indeterminación de la categoría de líder social como primera dificultad para la lucha contra la impunidad}

1 La primera dificultad, para alguien que quiera involucrarse con la defensa de la vida de los líderes sociales en Colombia, es poder determinar qué se entiende por líder social. En este sentido, los organismos del Estado se basan frecuentemente en la categoría de defensor de derechos humanos establecida por la ONU para definir su labor. Dicha categoría refiere a la persona que se dedica a promover y procurar la protección y realización de los derechos humanos y las libertades fundamentales en los planos nacional e internacional, tanto de forma individual como colectivamente, sin que exista una lista exhaustiva de las actividades que en ese sentido desarrolla. Según la ONU, cualquier persona o grupo de personas que promueva los derechos humanos, sea informalmente, a través de ONG, organizaciones intergubernamentales, o incluso desde entidades del Estado o del sector privado, puede ser parte de esta categoría. El criterio para determinar quién es líder social, según esta definición, es la actividad realizada y no la formalidad organizativa en la que se desempeñe la misma ${ }^{1}$.

2 A su turno, la Comisión para el Esclarecimiento de la Verdad adelantó una campaña permitiendo que fueran los líderes sociales mismos quienes se definieran. Estas 
definiciones propias designan personas comprometidas y con un grado de incidencia importante para la defensa de causas estratégicas en sus territorios, como la defensa de la cultura, el medio ambiente, la diversidad racial, la identidad y los derechos humanos, entendidos en una extensa variedad que incluye desde los de las minorías raciales, étnicas y culturales hasta los derechos sociales, económicos y culturales. Sin embargo, en numerosos casos, los líderes sociales no se reconocen como tales, lo cual se explica en parte porque en los sectores de ONG y entidades sin ánimo de lucro a las que frecuentemente pertenecen, el propósito de la organización es más importante que la contribución individual (Carreras, I. y A. Leaverton, 2009).

3 Esta indeterminación de la categoría de líderes sociales y de los criterios para establecerla redunda en la imposibilidad de conocer cifras unificadas en cuanto a amenazas, asesinatos sectores en riesgo, y territorios donde se concentran, lo que tiene consecuencias en la lucha contra la impunidad y la prevención de estos crímenes. Lo anterior trae consigo una mayor discrecionalidad de los operadores judiciales y administrativos, de suerte que muchos líderes quedan por fuera de las medidas de protección establecidas y que, en el caso de los asesinatos, las investigaciones adelantadas no sean orientadas a establecer los móviles y las responsabilidades no solo materiales sino intelectuales de esos crímenes. Como factor agravante, quienes hacen el monitoreo de las amenazas y los asesinatos no siempre pueden basarse en un trabajo directo de terreno, sino muchas veces a través de la información recibida a distancia, siendo diferentes entonces las cuentas de las comunidades y la de los organismos institucionales.

\section{El no reconocimiento de la sistematicidad de estos crímenes y la falta de garantías para consolidar el Acuerdo de Paz}

4 El Acuerdo de Paz firmado entre el gobierno colombiano y la guerrilla de las FARC posibilitó la inclusión de los ex guerrilleros en las instancias democráticas, como la creación de espacios de participación de sectores de la ciudadanía que tradicionalmente habían sido excluidos del debate político. Con ocasión de esa participación activa en el ejercicio y defensa de sus derechos individuales y colectivos, firmantes del Acuerdo de Paz se encuentran amenazados tanto por grupos paramilitares de extrema derecha (que actúan al margen de la ley y que rechazan los acuerdos de paz firmados por el anterior gobierno), como por grupos disidentes de las FARC y la guerrilla del ELN.

5 En el Acuerdo de Paz, se estableció la necesidad de implementar medidas de protección a los líderes sociales con un enfoque diferencial, territorial y de género. Sin embargo, en el contexto del post-acuerdo, se resaltan patrones de riesgo adicional, sin que hayan sido tomadas medidas diferenciales efectivas para líderes sociales que han participado activamente en la sustitución de cultivos ilícitos, indígenas y afrodescendientes en defensa activa de sus territorios, y quienes resisten al despojo ilegal de tierras. Tampoco se organiza la protección de quienes resisten a los proyectos de explotación extractivista, es decir aquellos que defienden el medio ambiente y condiciones de vida sostenibles frente a los desafíos que a nivel mundial presenta el cambio climático.

6 El reconocimiento de la sistematicidad de estos asesinatos ha sido activamente defendido por diversos sectores de la ciudadanía y organizaciones no gubernamentales. Conlleva a reconocer la existencia de un plan general para el exterminio de los líderes amenazados, de un aparato criminal con una estructura jerárquica y organizada, de 
patrones en su repetición frecuente y no accidental. Implica responsabilidades por parte del Estado con consecuencias a nivel internacional, así como admite la necesidad de ser abordada con un enfoque macrocriminal (Andrade, G., 2020).

7 A nivel institucional, la diversidad de las posiciones presentadas se puede explicar por la permanencia de funcionarios que venían del gobierno del presidente Santos, que le había apostado a los Acuerdos de Paz:

La Procuraduría General de la Nación es el máximo organismo del Ministerio Público encargado de representar a los ciudadanos ante el Estado, vigilar y controlar las actuaciones de los servidores públicos, e intervenir ante las diferentes instancias jurisdiccionales para la defensa de los derechos y garantías fundamentales. En cabeza del Procurador, Fernando Carrillo, ha reconocido la sistematicidad en estos crímenes, en especial el de los líderes reclamantes de tierras y ha adelantado investigaciones sobre la participación de agentes de la fuerza pública cooptados por organizaciones criminales para la eliminación de líderes.

(Procuraduría General de la Nación, 2018)

Conforme a este reconocimiento, ha adelantado una serie de iniciativas tendientes a la protección de los líderes sociales, entre ellas la expedición de la directiva 002 del 2017 para el cumplimiento de la cual se crearon delegaciones especiales y en los territorios atribuciones especiales a algunos funcionarios para el seguimiento de estas denuncias. Igualmente, la Defensoría del Pueblo, entidad adscrita, cumple un papel relevante. Sin embargo, la elección de la nueva Procuradora que se posesiona a comienzos del 2021 puede significar una variación en cuanto al compromiso de la Procuraduría para la protección de los líderes.

9 La Fiscalía General de la Nación, organismo encargado de adelantar el ejercicio de la acción penal e investigar los hechos delictivos, ha sido menos garantista que la Procuraduría en cuanto a la sistematicidad de estos crímenes. En el 2017, mediante la directiva 02, la Fiscalía estableció los lineamientos generales sobre la investigación de los delitos cometidos contra los líderes sociales, estableciendo las particularidades con las que esas investigaciones deben ser adelantadas, atendiendo los estándares internacionales de justicia como producto del diálogo con la Comisión Interamericana de Derechos Humanos. Si bien el anterior Fiscal General había reconocido en el 2019 la sistematicidad de estos crímenes, el alcance de ese reconocimiento se orientaba a investigar estructuras criminales operantes en los territorios, descartando de plano la posible participación de agentes del Estado. El actual Fiscal General de la Nación optó por negar la sistematicidad de esos crímenes, lo cual repercute en la ineficacia de las acciones de protección y en materia de impunidad.

La Corte Constitucional cumple un rol fundamental como máximo organismo de garantía de protección de los derechos fundamentales: en diferentes pronunciamientos ha establecido la necesidad de brindar una protección y plena garantía de los derechos de los líderes sociales como sujetos de especial protección refiriéndose particularmente a los grupos indígenas y afrodescendientes, así como ha establecido a través de múltiples sentencias criterios de apreciación de los hechos constitutivos de una amenaza para establecer la protección especial del Estado y las herramientas conceptuales para identificar el nivel de riesgo.

11 Para terminar, otro organismo determinante para la protección de los líderes sociales en el diseño institucional colombiano y en términos prácticos es la Unidad Nacional de Protección, organismo de seguridad adscrito al Ministerio del Interior encargado de desarrollar estrategias para el análisis y evaluación de los riesgos, amenazas y 
vulnerabilidades. También es competente para implementar las medidas de protección individuales o colectivas de las poblaciones en riesgo. El principal desafío que enfrentan los líderes para obtener la cobertura oportuna de medidas de protección por parte de este organismo es el de los trámites que, en condiciones de riesgo inminente, resultan engorrosos. Otro obstáculo es la ausencia de recursos, tanto para la cobertura de los líderes en situaciones de riesgo, como para la asignación de medidas de protección eficaces. Los esquemas de seguridad resultan insuficientes en buena parte de los casos, de cara a los niveles de riesgo.

12 A nivel interno, parecen necesarios tanto el reconocimiento de la sistematicidad de esos asesinatos, como una mejor coordinación entre los diferentes actores involucrados con la protección de la vida de los líderes sociales a nivel Estatal y de la sociedad civil, y en ese sentido, la creación de un organismo que pueda concentrar todos los esfuerzos orientados a este fin.

\section{En el ámbito internacional de protección}

13 Ante la imposibilidad de una respuesta efectiva para la garantía de la protección de la vida de los líderes sociales en las vías internas, es preciso revisar cuales han sido los roles del sistema Internacional de Justicia y de los organismos internacionales para que estos vacíos se puedan colmar.

\section{La aproximación de la Comisión Interamericana de Derechos Humanos (CIDH)}

14 En diversos pronunciamientos, la Comisión ha reiterado su preocupación por los asesinatos de líderes sociales. En su informe de diciembre de 2019, tras su visita a Colombia, la CIDH emitió 13 recomendaciones e impuso medidas cautelares para proteger a los líderes. Estas recomendaciones fueron reiteradas en la entrega del informe del 23 de junio de 2020, lo que demuestra que no han avanzado las instituciones, en especial en cuanto a: 1) enfoques diferenciales en las medidas de protección; 2) erradicación de las causas de riesgo identificadas, como competencia por el control de las economías ilegales y criminalidad organizada; 3) lenta estabilización de territorios que eran de las FARC.

Por otra parte, su Relatoría Especial para la Libertad de Expresión manifestó su preocupación ante denuncias de una presunta red de espionaje ilegal a medios de comunicación, periodistas, defensoras y defensores de derechos humanos, magistradas y magistrados, y dirigentes políticos, que habría sido desarrollada por agentes estatales en Colombia - lo cual participó en el escenario hostil para la defensa de los derechos humanos.

16 Asimismo, en el contexto de la pandemia mediante la resolución No 1 del 10 de abril de 2020 en la que se estableció una serie de recomendaciones para los países de la Región, la Comisión refirió los impactos diferenciados e interseccionales sobre la realización de los derechos económicos, sociales, culturales y ambientales (DESCA) para colectivos y poblaciones en especial situación de vulnerabilidad, destacando entre ellos a los líderes sociales. Lo anterior no ha tenido eco en materia de protección teniendo en cuenta la intensidad que mantienen los asesinatos en el contexto de la emergencia, mientras que 
entidades de protección como las mesas regionales de garantías han dejado de funcionar.

17 En el mismo sentido, el Comité de los DESC, mediante observación General No 25 de abril de 2020, determinó que los estados de excepción no podían afectar los derechos políticos ni restringir el acceso a las protecciones judiciales efectivas, y que ese contexto obliga a reforzar la protección de los derechos políticos.

\section{La aproximación de la CPI, la ONU y el Parlamento Europeo}

18 En 2004, la CPI abrió un examen preliminar de forma general sobre desapariciones forzadas y ejecuciones extrajudiciales en Colombia, pero no se conocen avances procesales sobre el caso. La misma Corte realiza en la actualidad un monitoreo de la situación de los líderes sociales en Colombia, que la ha llevado en varias oportunidades a realizar una serie de recomendaciones. Sin embargo, la experiencia de la CPI desde su apertura en el 2002 demuestra un margen de acción limitado: esa jurisdicción actúa bajo el principio de complementariedad únicamente ante la ausencia de garantías en el ámbito interno.

Ahora bien, en el sistema internacional, la impunidad del asesinato de los líderes sociales ha llamado la atención de distintas oficinas de las Naciones Unidas que tienen la mirada fijada hacia Colombia por los compromisos internacionales contraídos con los países garantes durante las negociaciones de paz. El ejecutivo ha rechazado, sin embargo, los informes de 2019 de la Oficina de la Alta Comisionada de las Naciones Unidas para los Derechos Humanos, y del Relator Especial para defensores de derechos humanos, que ponen en evidencia las fallas en la política de seguridad como en la implementación del Acuerdo de Paz.

20 El retraso en la implementación del acuerdo y en especial de la reforma rural integral y el desarrollo de los Programas de Desarrollo con Enfoque Territorial y de programas de sustitución de cultivos ilícitos, se presentan como un incumplimiento a los compromisos internacionales del Estado. Por otra parte, falla en no atacarse a las causas estructurales de los asesinatos, las cuales son vinculadas a las disputas territoriales entre grupos armados, como bien lo documentan los informes de organizaciones como Somos Defensores, INDEPAZ, e incluso la Defensoría del Pueblo, que constituyen un importante arsenal probatorio.

21 Lo anterior tiene incidencia económica, puesto que en el marco del acompañamiento de la comunidad internacional al Acuerdo de Paz, el Estado recibe una ayuda económica importante de la Unión Europea para atacar las causas del conflicto. Así pues, además de la competencia de cortes internacionales, esta serie de incumplimientos pueden acarrear sanciones de tipo económico desde la comunidad internacional hacia el Estado colombiano. En este sentido, 137 parlamentarios europeos solicitaron la aplicación de la cláusula democrática y de DDHH en octubre del 2020, con el propósito de suspender el acuerdo comercial con los sectores económicos particularmente beneficiados con los asesinatos y desplazamientos de la población colombiana. A pesar de no haber ganado los votos de la mayoría de los parlamentarios, dicha cláusula abre posibilidades para incidir internacionalmente y sancionar la continuidad de este flagelo.

En últimas, la protección de la vida de los líderes sociales en Colombia está lejos de ser un asunto de interés y trascendencia meramente nacional. Los esfuerzos para lograr 
materializarla deben estar orientados con la misma intensidad tanto en el ámbito interno como en el ámbito internacional.

\section{BIBLIOGRAFÍA}

Carreras, Ignasi, Leaverton, Amy y Sureda, María,"Líderes para el cambio social, características y competencias del liderazgo en las ONG”, Universidad Ramon Llull y Fundación PWC, 2009, p 18.

Centro de Pensamiento y Diálogo Político, "Estado General de la Implementación del Acuerdo de Paz en Colombia, En Claroscuro", Ed Gentes del Común, enero de 2020.

Procuraduría General de la Nación, "Violencia sistemática contra defensores de derechos territoriales en Colombia" Informe P, abril de 2018.

Rojas Andrade, Gabriel, "El homicidio de líderes sociales es un fenómeno sistemático y macrocriminal", en Revista 070, Universidad de los Andes, disponible en línea: https:// cerosetenta.uniandes.edu.co/lideres-asesinados-2020, consultado el 20 de diciembre de 2020.

\section{NOTAS}

1. Ver https://www.ohchr.org/SP/Issues/SRHRDefenders/Pages/Defender.aspx y el Informe del Relator Especial sobre la situación de los defensores de los derechos humanos, A/73/215, 23 de julio de 2018, párr. 15.

\section{AUTOR}

\section{CIELO E. RUSINQUE URREGO}

Abogada de la Universidad Externado de Colombia. Especialista en Derecho Constitucional de la Universidad Paris II Panthéon-Assas. Master de investigación en Estudios Políticos de esta misma Universidad. Candidata a Doctor en Derecho Constitucional de la Universidad Paris II PanthéonAssas. 